\title{
Hybridization and Mission Analysis of a Regional Turboprop
}

\author{
F. Orefice ${ }^{1}$, F. Nicolosi ${ }^{2}$, S. Corcione ${ }^{3}$, \\ P. Della Vecchia ${ }^{4}$, D. Ciliberti ${ }^{5}$, M. Ruocco ${ }^{6}$ \\ University of Naples "Federico II", Naples, 80125, Italy - DAF Research Group \\ (www.daf.unina.it)
}

The potential benefits of hybrid-electric or full-electric propulsion have led to the proliferation of many concepts over the past decade. However, in most cases, concepts are referred to aircraft designed starting from early stages of the design process requiring a specific manufacturing chain. This could lead to aircraft which are less appetible in an industrial or economic sense. The present work proposes a complete application of the design process proposed by the authors in recent publications to refit the propulsive system of an already flying regional turboprop. The hybridization process requires the evaluation of many different powertrain architecture to find the most suited to maximize the fuel saving percentage. The resize of thermal and electric components is based on the power requirements provided by a simulation-based analysis of the mission profile. The reference aircraft is similar to ATR-42.

\section{Nomenclature}

$(\cdot)_{1} \quad=$ subscript for primary propulsive system

$(\cdot)_{2}=$ subscript for secondary propulsive system

$C_{(\cdot)} \quad=$ aerodynamic coefficient

$E \quad=$ energy

$P \quad=$ power

$S \quad=$ wing planform area

$W \quad=$ weight

$A_{s} \quad=$ cross-sectional area of the slipstream

$A_{p} \quad=$ area of the disk propeller

$T \quad=$ thrust

$V_{(\cdot)} \quad=$ velocity at the location $(\cdot)$

$a_{(\cdot)} \quad=$ axial induction at the location $(\cdot)$

$\varphi=$ shaft power ratio

$\Phi=$ = supplied power ratio

$\eta \quad=$ efficiency

$\chi=$ thrust hybridization factor

OEW = Operative Empty Weight

MZFW = Maximum Zero Fuel Weight

MTOW $=$ Maximum Take-off Weight

\footnotetext{
${ }^{1}$ PhD Student, DAF Research Group, Dept. of Industrial Engineering.

${ }^{2}$ Associate Professor, DAF Research Group, Dept. of Industrial Engineering, AIAA Member.

${ }^{3}$ Assistant Professor, DAF Research Group, Dept. of Industrial Engineering.

${ }^{4}$ Assistant Professor, DAF Research Group, Dept. of Industrial Engineering, AIAA Member.

${ }^{5}$ Assistant Professor, DAF Research Group, Dept. of Industrial Engineering.

${ }^{6}$ Post-Doc, DAF Research Group, Dept. of Industrial Engineering.
} 


$\begin{array}{ll}\text { PMAD } & =\text { Power Management And Distribution } \\ \mathrm{OEI} & =\text { One Engine Inoperative } \\ \mathrm{AEO} & =\text { All Engine Operative } \\ \text { TLAR } & =\text { Top Level Aircraft Requirements }\end{array}$

\section{The challenges of (hybrid) electric regional turboprop}

The proven impact of electric technologies on reduction of emissions has led to innovative concepts and many research projects have been specifically dedicated to underly the critical points and the major advantages resulting from different powertrain architectures. Hybrid-electric and full-electric concepts proposed in literature already explored any possible powertrain architecture, but even if the promising results in terms of fuel saving would encourage this path for the future aviation, some issues remain unsolved. The present work deals with two main issues derived from previous works and projects. The first and major issue deals with the technological level required to electrify a regional turboprop. This could be a limiting factor when coming to the battery specific energy which is the main responsible of the increment in max take-off weight. In Table 1, the dependence of range from the specific energy of the battery is shown as a common trend to all aircraft categories, regardless from regulation or concept. However, since the main objective of the present work is a feasibility study of a hybrid-electric concept which would provide reliable results for a close future, the specific energy density will be fixed to values which are close to the state of the art, that is $350 \mathrm{Wh} / \mathrm{kg}$. Considering this weight, an additional contribution to the total weight of the battery pack will be considered in terms of thermal management system and cell management system which would result in a global specific energy of $250 \mathrm{Wh} / \mathrm{kg}$.

Table 1. Electric Aircraft Projects.

\begin{tabular}{|c|c|c|c|c|c|}
\hline & $\begin{array}{l}\text { Powertrain } \\
\text { architecture }\end{array}$ & Category & $\begin{array}{l}\text { Battery Specific } \\
\text { Energy }(\mathrm{Wh} / \mathrm{kg})\end{array}$ & $\begin{array}{c}\text { Number } \\
\text { of } \\
\text { Passenger }\end{array}$ & $\begin{array}{c}\text { Design } \\
\text { Range } \\
\text { (Nmi) }\end{array}$ \\
\hline Airbus E-Fan $\mathbf{X}^{1}$ & Hybrid-electric & Large Aircraft & 207 & 100 & 151 \\
\hline Eviation Alice $^{2}$ & Hybrid-electric & Commuter Aircraft & 260 & 9 & 540 \\
\hline NASA Pegasus [1] & Hybrid-electric & Regional Turboprop & 500 & 48 & 400 \\
\hline Boeing Sugar Volt [2] & Hybrid-electric & Large Aircraft & 750 & 154 & 3500 \\
\hline
\end{tabular}

As for the battery characteristics, the e-motor drive technological level employed for the hybridization process is close to the state of the art and additional masses are considered for inverter and thermal management system. In the following table, the description of the technological levels in terms of battery and e-motor drive characteristics is reported.

Table 2. Electric Aircraft Projects.

\begin{tabular}{lcc}
\hline \hline & Value & Unit \\
\hline Battery Specific Energy & 350 & $\mathrm{Wh} / \mathrm{kg}$ \\
Battery Specific Power & 1 & $\mathrm{~kW} / \mathrm{kg}$ \\
Battery Energy Density & 800 & $\mathrm{Wh} / \mathrm{l}$ \\
E-Motor Drive Specific Power & 7.0 & $\mathrm{~kW} / \mathrm{kg}$ \\
\hline \hline
\end{tabular}

In the present work, attention is given to the regional turboprop aircraft (ATR-42) category, as main example of promising results obtained even in case of technological levels which are close to the state of the art. Results here proposed are part of the IRON project, aiming to hybridize a regional turboprop without requiring major changes of the productive chain, which is an indispensable benefit for the industrial advantage. This is the second issue since it would impose limited changes to the baseline structure and concept resulting in a maximum allowable increment of the aircraft weight. However, targeting an entrance in service for year 2025, the choice of technological level close to the state of the art and a maximum take-off weight of 24 tons to prevent major changes to the aircraft structure are mandatory. Stated these two issues, the solution would be profitable in economic terms if a significative block fuel reduction of the typical mission is obtained.

\footnotetext{
${ }^{1}$ https://www.airbus.com/innovation/zero-emission/electric-flight/e-fan-x.html

${ }^{2}$ https://www.eviation.co/aircraft
} 
To enhance the estimation of the impact that hybrid-electric propulsion has on aircraft flight mission parameters, it is fundamental to perform detailed simulation-based mission analyses [3]. A simulation-based analysis can be realized only characterizing each single step of the whole flight mission of an aircraft by its aerodynamics and propulsive features. Therefore, all the aspects defining the aircraft state at each step, such as Mach number, altitude, throttle setting, acceleration, rate of climb, etc., must be determined to simulate the flight history.

\section{Hybridization process of ATR-42}

The regional turboprop aircraft has attracted the interest of many researcher and designer after the early prototypes of hybrid-electric CS-23 [4] (or FAR-23) aircraft flew. The turboprop category was identified as the following step to approach CS-25 (or FAR-25) [5] certified aircraft for the hybridization of the global fleet, but the power and energy requirements of conventional aircraft appeared to be prohibitive and, sometimes, results in terms of design range and performance of hybrid concepts were unsatisfactory with respect to the conventional ones. One of the objectives of this work is to assess the possible advantages and drawbacks of hybrid/electric aircraft with respect to a conventional aircraft selected as a reference baseline. In the present case, the top-level requirements and performance considered in case of ATR-42 will be proposed for the hybrid-electric concept to underly the possible disadvantages related to the weight increment due to battery and additional powertrain elements.

The design process proposed in literature for hybrid-electric aircraft is composed by different steps starting from point performance [6]. However, when the geometry and the structural masses are frozen, a different approach can be considered stepping in the design process from the simulation-based mission analysis, changing some design parameters of interest while remaining compliant with performance requirements [7,8]. At this point, since the only mass changing depends on the propulsive system, the first step is the definition of the frozen masses related to structural weights. The hybrid-electric configuration chosen is similar to NASA Pegasus concept [9], but the thermal engine will be fixed in the same position of the reference aircraft to limit the load variations over the wing. This concept has the advantage to require minor changes in the propulsive architecture. Moreover, the power split on two propellers will be enough to increase the thrust without affecting the propulsive efficiency. To describe the propulsive system in terms of power split among the two different propulsive lines and from the two different power sources (fuel and e-storage), two hybridization factors [10] are here introduced: the supplied power ratio $\Phi=\frac{P_{\mathrm{E}-\text { storage }}}{P_{\text {fuel }}+P_{\mathrm{E}-\text { storage }}}$ and the shaft power ratio $\varphi=\frac{P_{\text {prop } 2}}{P_{\text {prop } 1}+P_{\text {prop } 2}}$

(2).

$$
\begin{aligned}
& \Phi=\frac{P_{\text {E-storage }}}{P_{\text {fuel }}+P_{\mathrm{E}-\text { storage }}} \\
& \varphi=\frac{P_{\text {prop 2 }}}{P_{\text {prop 1 }}+P_{\text {prop 2 }}}
\end{aligned}
$$

Where the subscript 1 (colored blue in Fig. 1) refers to the propulsive units directly powered by the thermal engine, whereas the tip mounted propeller, which is directly connected to the electric motors, is addressed as secondary propulsive system andidentified by the subscrint 2 (colored red in Fig 1)

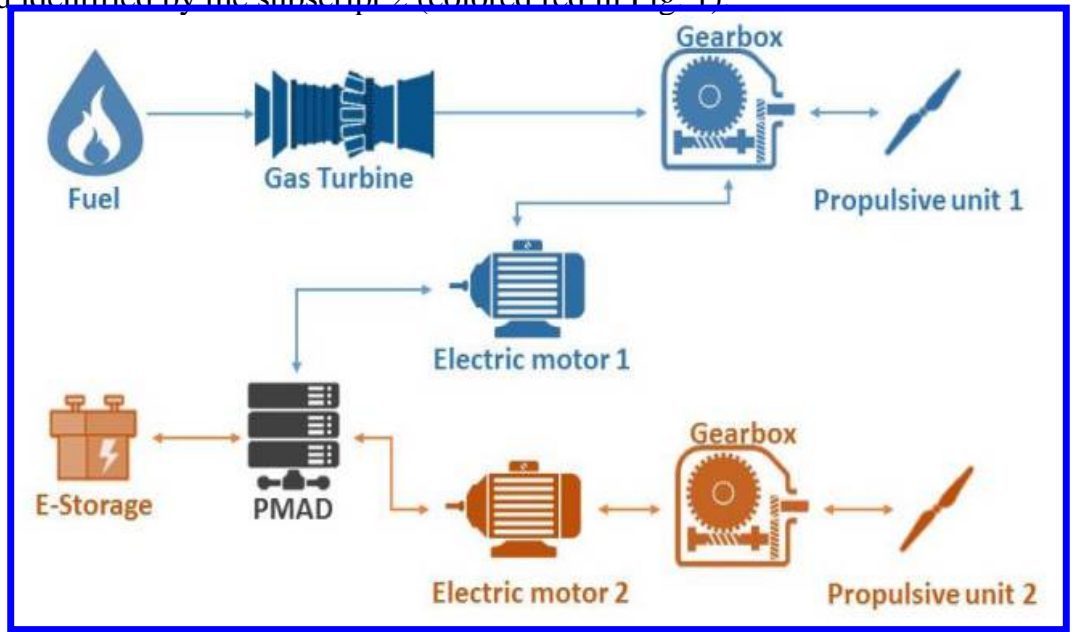

Fig. 1 The most general propulsive architecture considered in the present work. 
A third hybridization parameter, necessary to estimate the variation of the aerodynamic coefficients' variation related to the aero-propulsive interactions $\left(\Delta C_{L}, \Delta C_{D_{0}}\right.$ and $\left.\Delta C_{D_{i}}\right)$, is defined as the ratio between the tip-mounted propeller thrust and the total thrust of the aircraft.

$$
\chi=\frac{1}{1+\frac{\eta_{P 1}}{\eta_{P 2}}\left(\frac{1-\varphi}{\varphi}\right)}
$$

When the masses of the baseline are stripped of the powertrain architecture, before proceeding with the mission analysis, the mass of the electric components and the thermal engine, as well as the sizing powers, are equal to zero. This is the first shot of the design loop which is an iterative process, as shown in Fig. 2. Moving from this, the flight mission and the compliance with the flight performance are checked. Each time the mass of fuel or the energy stored in the battery, or the power required by a certain flight phase are not enough, the mentioned characteristics are updated to higher values depending on the requirements calculated. This is an iterative process strictly dependent on the powertrain characteristics assumed and on the supplied and shaft power ratios.

A wide set of shaft power ratio and supplied power ratio is explored in order to find the most suited powertrain architecture to maximize the fuel saving percentage. However, since the different phases can have different values of shaft power and supplied power ratios, the different permutations would be a prohibitive number to investigate. Thus, some hypotheses are necessary. The mission profile is divided in flight phases: take-off, first segment of climb (up to $10000 \mathrm{ft}$ ), climb to cruise, cruise, descent, approach and landing. The reserve phases (alternate and loiter) are included in the present work as part of the mission profile, but completely flown using the thermal power source $(\Phi=0)$. This is the first limiting hypothesis proposed. The second one deals with the dimensioning requirements of the e-storage. Since the main objective is maximizing the block fuel saving percentage on the typical mission, the present work proposes to size the battery on the typical mission requirements. Moreover, since the sizing power of the thermal components is often related to climb and take-off, the use of e-storage with high values of supplied power ratio in those phases can reduce the thermal engine power and weight (at equal max take-off weight). The last hypothesis is about the maximum power delivered to the tip-mounted propellers. Since the wing structure has been fixed, the tipmounted mass should be limited to avoid a lowering of the flutter speed [6,7]. The value of shaft power ratio fixed for this reason is 0.3. In the end, different algorithms can be considered to explore the possible permutations of supplied and shaft power ratios, but, regardless to the choice, the procedure should optimize the use of battery during the typical mission while keeping the maximum take-off weight of the design mission around $24000 \mathrm{~kg}$. The proposed solution is one of the most promising, stated the preceding hypothesis, but still not the only possible.

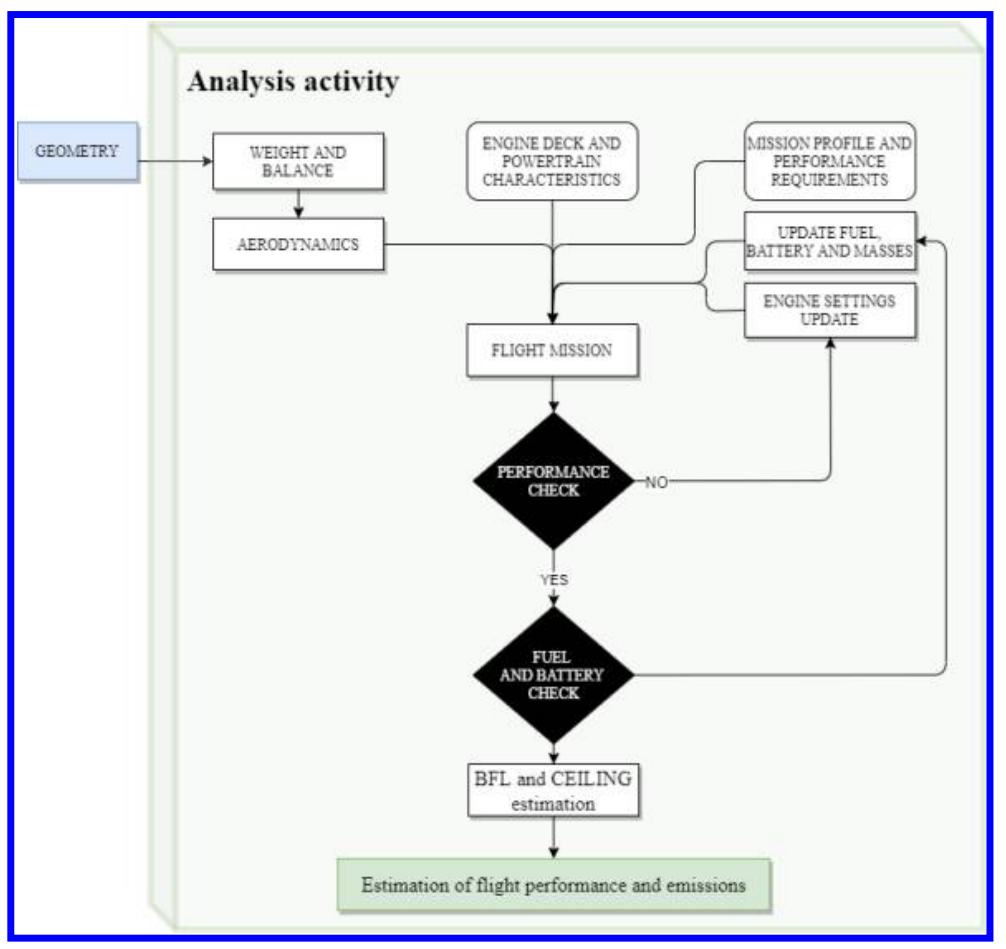

Fig. 2 Workflow of the design process proposed. 


\section{Reference aircraft and Top-Level Aircraft Requirements}

Approaching the design of innovative configurations and hybrid-electric aircraft, the validation benchmark of the design method cannot be other than a conventional flying platform. In the present case, the incremental innovation of an aircraft similar to the ATR-42 platform imposes a direct comparison with the conventional version of the aircraft. The main geometrical characteristics are summarized in Table 4.

The geometrical characteristics are frozen for both configurations considered in the present work, but this is still compliant with the innovative concept since technologies designed to reduce the wing area (e.g.: blown flap and distributed electric propulsion) are out of the intent. Even if most of ATR-42 data are available, to make a fair comparison between the two platforms, the mission profile is analyzed considering the same software, validated by comparison with other tools $[13,14]$, and thermal engine deck (which will be scaled depending on the specific requirements of the two aircraft). Mission requirements shown in the following table have been considered both for the conventional baseline and the hybrid-electric concept.

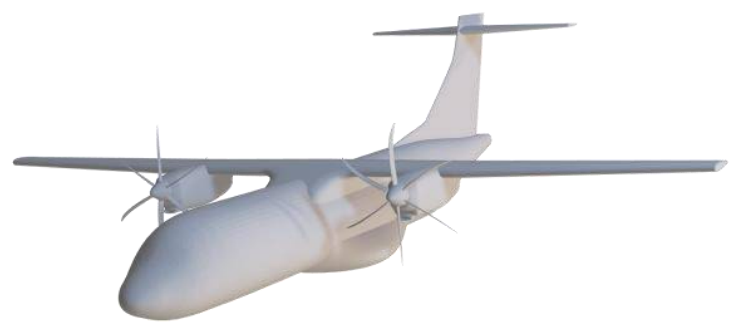

Fig. 3 Reference aircraft.

Table 4. Geometric characteristics of ATR-42.

\begin{tabular}{lcc}
\hline \hline & Value & Unit \\
\hline Wing surface & 54.5 & $\mathrm{~m}^{2}$ \\
Wingspan & 24.57 & $\mathrm{~m}$ \\
Wing AR & 11.07 & \\
Horizontal Tail surface & 10.58 & $\mathrm{~m}^{2}$ \\
Horizontal Tail span & 7.10 & $\mathrm{~m}$ \\
Horizontal Tail AR & 4.76 & \\
Vertical Tail surface & 12.53 & $\mathrm{~m}^{2}$ \\
Vertical Tail span & 4.55 & $\mathrm{~m}$ \\
Vertical Tail AR & 1.65 & \\
Fuselage Length & 22.67 & $\mathrm{~m}$ \\
Cross section height & 2.65 & $\mathrm{~m}$ \\
Cross section width & 2.86 & $\mathrm{~m}$ \\
Distance between engines & 8.10 & $\mathrm{~m}$ \\
Propeller diameter & 3.93 & $\mathrm{~m}$ \\
Wheel track & 4.10 & $\mathrm{~m}$ \\
Wheelbase & 8.86 & $\mathrm{~m}$ \\
\hline \hline
\end{tabular}

Table 3. Mission Requirements.

\begin{tabular}{lcc}
\hline Design Mission & Value & Unit \\
\hline Cruise Range & 600 & $\mathrm{nmi}$ \\
Cruise Mach Number & 0.46 & - \\
Cruise Altitude & 25000 & $\mathrm{ft}$ \\
Diversion Range & 100 & $\mathrm{nmi}$ \\
Diversion Mach Number & 0.27 & - \\
Diversion Altitude & 10000 & $\mathrm{ft}$ \\
Loiter Time & 30 & $\mathrm{~min}$ \\
Loiter Altitude & 1500 & $\mathrm{ft}$ \\
Calibrated Climb Speed & 160 & $\mathrm{kts}$ \\
Calibrated Descent Speed & 220 & $\mathrm{kts}$ \\
\hline Typical Mission & & \\
\hline Cruise Range & 200 & $\mathrm{nmi}$ \\
Cruise Mach Number & 0.46 & - \\
Cruise Altitude & 27000 & $\mathrm{ft}$ \\
Diversion Range & 100 & $\mathrm{nmi}$ \\
Diversion Mach Number & 0.27 & - \\
Diversion Altitude & 10000 & $\mathrm{ft}$ \\
Loiter Time & 30 & $\mathrm{~min}$ \\
Loiter Altitude & 1500 & $\mathrm{ft}$ \\
Calibrated Climb Speed & 160 & $\mathrm{kts}$ \\
Calibrated Descent Speed & 220 & $\mathrm{kts}$ \\
\hline Performance & & \\
\hline Balanced Field Length & $<1100$ & $\mathrm{~m}$ \\
Ceiling Altitude (AEO) & $>27000$ & $\mathrm{ft}$ \\
Ceiling Altitude (OEI) & $>14000$ & $\mathrm{ft}$ \\
\hline \hline
\end{tabular}

It is here highlighted that the balanced field length and the ceiling altitude play a major role when resizing the propulsive system components. In fact, to be compliant with performance requirements, while the maximum take-off weight (MTOW) increases, thrust required increases as well. Thrust requirements derived for the present configuration driven the design of the engine deck. The analysis tool can manage different powertrain architectures, even when the same propeller is powered by two different power sources. When e-storage and fuel are both considered, it would be difficult to relate the fuel consumption to the shaft power or thrust, thus, the thermal engine deck is modeled from the specification requirements in terms of fuel flow and gas-turbine (GT) power. The energy can follow different paths depending on the operating modes considered and reported in Table 5. In general, the dimensioning power for each component is the power entering in the electric element. The gasturbine is dimensioned to the maximum exiting power. The battery is dimensioned to the maximum among the exiting power and the energy requirement. 
Table 5. Hybrid-electric powertrain operating modes [10].

\begin{tabular}{lcccccccccc}
\hline \hline & $\mathbf{1}$ & $\mathbf{2}$ & $\mathbf{3}$ & $\mathbf{4}$ & $\mathbf{5}$ & $\mathbf{6}$ & $\mathbf{7}$ & $\mathbf{8}$ & $\mathbf{9}$ \\
\hline P1 & thrust & thrust & thrust & thrust & thrust & thrust & harvest & harvest & harvest \\
P2 & thrust & thrust & harvest & thrust & harvest & harvest & thrust & thrust & harvest \\
E-Storage & discharge & charge & charge & discharge & discharge & charge & discharge & charge & charge \\
EM1 & generator & generator & generator & motor & motor & motor & generator & generator & generator \\
\hline \hline
\end{tabular}

The engine deck defined in terms of gasturbine power is the starting point for the estimation of the propulsive power a

n

d

$\mathrm{h}$

r

$\mathrm{u}$

S

$\mathrm{t}$

$$
\left\{\begin{array}{c}
P_{g t}=P_{f} \eta_{G T} \\
P_{s 1}+P_{g b}=P_{g t} \eta_{G B} \\
P_{p 1}=P_{s 1} \eta_{P 1} \\
P_{e 1}=P_{g b} \eta_{E M 1} \\
P_{e 2}=P_{b a t} \eta_{P M}+P_{e 1} \eta_{P M} \\
P_{s 2}=P_{e 2} \eta_{E M 2} \\
P_{p 2}=P_{s 2} \eta_{P 2} \\
P_{p}=P_{p 1}+P_{p 2} \\
\Phi=\frac{P_{b a t}}{P_{b a t}+P_{f}}
\end{array}\right.
$$

$\mathrm{t}$

$\mathrm{e}$

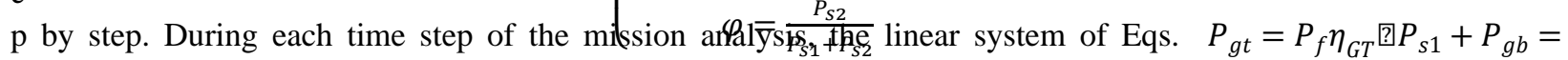
In the present case, since ATR-42 thermal engine deck, that is PW127 E/M engine deck, is not available, a certain turboprop model has been fixed and for each engine setting, the gasturbine power has been obtained considering the efficiency of the single powertrain elements.

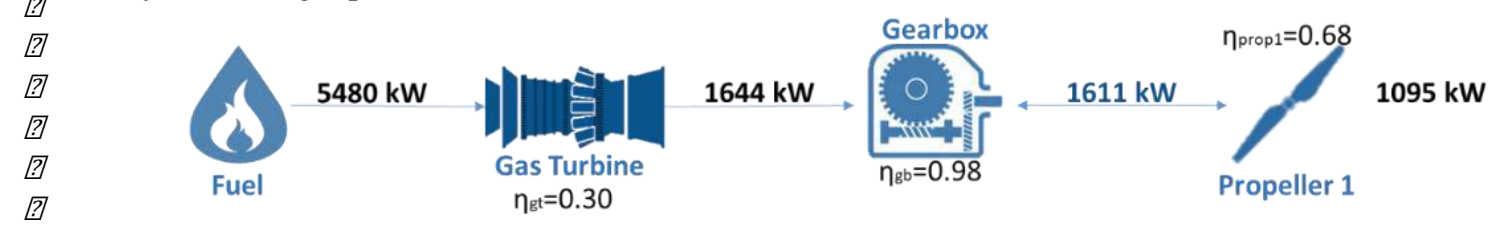

Fig. 4 Power and efficiencies for the turboprop engine model considered for the first shot of the iterative loop.

27 Reference aircraft masses and performance are here reported.

2]

2

?

20

1

(2)

(2)

(2)

(2)

1

2]

20

2?

27

1

?

[?

?

Table 6. Mass breakdown.

\begin{tabular}{lcc}
\hline \hline Design Mission & Value & Unit \\
\hline MTOW & 18525 & $\mathrm{~kg}$ \\
ZFW & 16534 & $\mathrm{~kg}$ \\
OEW & 11974 & $\mathrm{~kg}$ \\
Structural Weight & 6465 & $\mathrm{~kg}$ \\
Powertrain Weight & 1384 & $\mathrm{~kg}$ \\
Fuel Weight & 1991 & $\mathrm{~kg}$ \\
Fuel Weight Consumed & 1892 & $\mathrm{~kg}$ \\
Block Fuel Weight & 1374 & $\mathrm{~kg}$ \\
Payload Weight & 4560 & $\mathrm{~kg}$ \\
\hline Typical Mission & & \\
\hline MTOW & 17618 & $\mathrm{~kg}$ \\
Fuel Weight & 1086 & $\mathrm{~kg}$ \\
Fuel Weight Consumed & 1030 & $\mathrm{~kg}$ \\
Block Fuel Weight & 513 & $\mathrm{~kg}$ \\
\hline \hline
\end{tabular}


Table 7. Performance of the reference aircraft.

\begin{tabular}{lcc}
\hline \hline & Value & Unit \\
\hline Take-Off run & 805 & $\mathrm{~m}$ \\
Landing run & 783 & $\mathrm{~m}$ \\
Balanced Field Length & 1030 & $\mathrm{~m}$ \\
Ceiling altitude OEI & 15348 & $\mathrm{ft}$ \\
Ceiling altitude AEO & 31348 & $\mathrm{ft}$ \\
\hline \hline
\end{tabular}

\section{Hybrid-electric regional turboprop}

The design of a completely new aircraft moves from a set of top-level aircraft requirements (TLAR) which can be fixed in relation to new market demands. In the present case, design requirements have been fixed by the existing baseline.

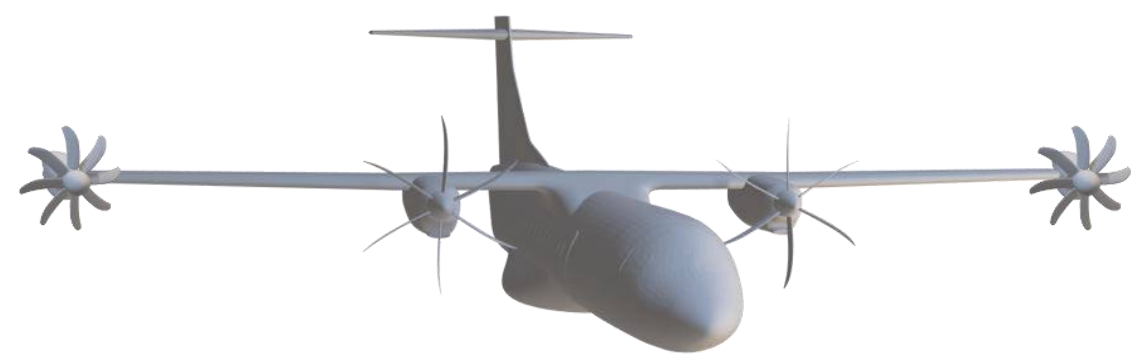

Fig. 5 Hybrid-electric regional turboprop.

The geometrical characteristics of the present concept are the same of ATR-42, however, an additional propeller of $2.95 \mathrm{~m}$ is added on the wingtip to the one already proposed in the conventional concept. The directional stability of the new configuration has been checked considering the one-engine-inoperative condition according to design methods from literature [15]. Moving from an engine deck like the one of ATR-42, based on gasturbine power and fuel flow, as discussed previously, the new thermal engine deck has been scaled linearly considering the hypothesis of small changes. By this model, the powertrain architectures presented in Fig. 6 can be modelled. Among them, three different architectures have been investigated for the present concept. Results shown in the present section refers to serial/parallel partial hybrid-electric architecture.

Before designing this concept, the powertrain mass has been subtracted by the reference aircraft weights so that the resulting mass of the new concept would include only the different weight of the powertrain (including the new required fuel). Thus, moving from the Maximum Zero Fuel Mass (MZFM) of the conventional aircraft at which the propulsive system mass has been subtracted, the weight of the propulsive system, including power sources, is added at each iteration of the design loop. Considering the maximum take-off weight limit to $24000 \mathrm{~kg}$, the maximum battery mass (excluding the thermal management system) has been estimated around $3000 \mathrm{~kg}$, that is $1050 \mathrm{kWh}$ in terms of corresponding energy. Thus, stated the mass limit and the consequent maximum stored energy, the objective of the design process is to find the set of design parameters, in terms of shaft power distribution among the two propulsive lines and supplied power coming from the fuel and e-storage, to maximize the fuel saving percentage. In the present work, what will be addressed as strategy profile is the way each component of the powertrain is used phase by phase (e.g.: the battery is recharging or discharging in a certain flight phase? How much shaft power is provided to the propulsive lines phase by phase? How much battery power should be provided phase by phase?). Since tip-mounted propellers has a minor impact on fuel saving, this second aspect is investigated posing more attention to the usage of battery phase by phase and, thus, to the supplied power ratio. Different sets of supplied power ratios can be used (e.g.: equal use in all phases or use of the battery more at take-off and climb than in other phases) giving the designer a wide range of possible concepts. Even when the battery weight and energy are fixed, the same total energy can be split differently phase by phase. Thus, when the concept has been chosen and the total energy of the battery fixed, the use of this battery phase by phase (or, in other words, the strategy profile) is the subject of the further optimization of the configuration. 


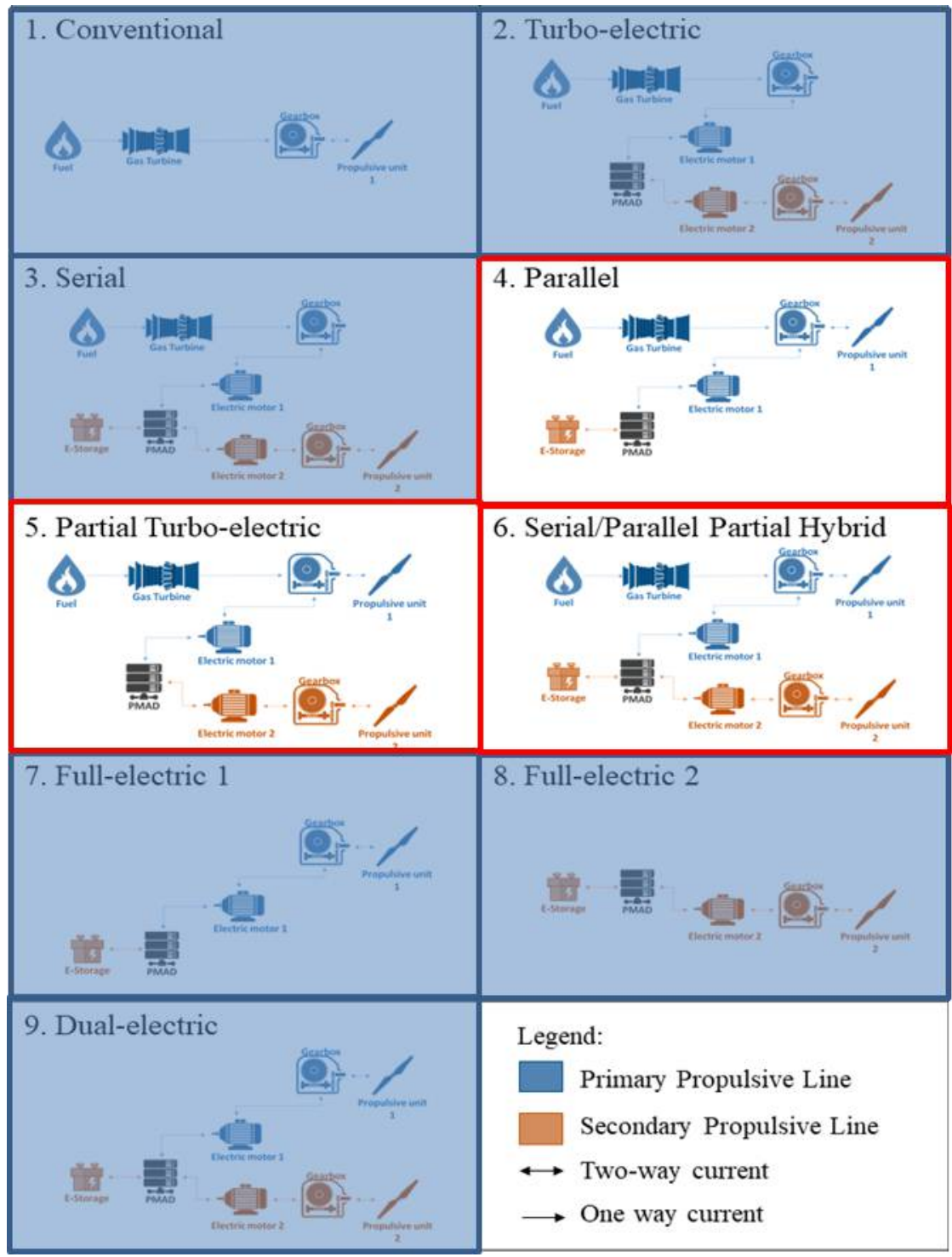

Fig. 6 Powertrain architectures considered.

The hybrid-electric concept mass breakdown is described in the following table.

Table 8. Mass breakdown.

\begin{tabular}{lcc}
\hline \hline Design Mission & Value & Unit \\
\hline MTOW & 24094 & $\mathrm{~kg}$ \\
ZFW & 21951 & $\mathrm{~kg}$ \\
OEW & 17391 & $\mathrm{~kg}$ \\
Structural Weight & 6465 & $\mathrm{~kg}$ \\
Battery Weight & 3000 & $\mathrm{~kg}$ \\
Powertrain Weight & 6801 & $\mathrm{~kg}$ \\
Fuel Weight & 2143 & $\mathrm{~kg}$ \\
Fuel Weight Consumed & 2041 & $\mathrm{~kg}$ \\
Block Fuel Weight & 1446 & $\mathrm{~kg}$ \\
Payload Weight & 4560 & $\mathrm{~kg}$ \\
\hline \hline
\end{tabular}


Differently from the reference aircraft, the typical mission masses are considered a variable of the following optimization since the fuel mass at frozen mission profile strongly depends on the battery usage phase by phase.

\section{Design and typical mission profiles simulation}

The typical and design missions proposed in the present work are the same for both concepts, but the importance of an optimal coupling of the shaft and supplied power ratios with the mission requirements and performance is an aspect investigated in case of hybrid-electric propulsive systems.

The number of design missions along the operative life of an aircraft is quite limited, thus, the use of the battery is optimized considering solely the typical mission. The design mission is here simulated with the only purpose to validate the operational flexibility of the hybrid-electric concept which should result to be the same of the reference aircraft. In the present section, as example of a single iteration of the design process, different combinations of supplied power ratios are coupled to one set of shaft power ratios. In order to identify the most promising concept, each set of shaft power ratios has been coupled to more sets of supplied power ratios to give birth to many different mission strategy profiles. Three different supplied power ratios sets are proposed and identified in Table 9. The coupling would provide 3 different simulations of the typical mission. However, when the shaft power ratio set changes, other sets of supplied power ratio are necessary to be sure that the battery energy is completely used (up to the minimum state of charge fixed around 20\%). In other words, each shaft power ratio set has its supplied power ratios sets associated which are calculated runtime, given certain constraints (e.g.: equal use of e-storage at take-off and climb), to be sure that the battery is efficiently used. At the same time, when the supplied power ratios change with respect to those used along the design mission, which is the sizing mission for the powertrain architecture, the thermal engine throttle is modified as well in order to adapt to the new power supplied by the e-storage and not exceeding the sizing power of each component.

Table 9. Typical Mission strategy profile for shaft power and supplied power ratios.

\begin{tabular}{|c|c|c|c|c|c|c|c|}
\hline \multicolumn{8}{|c|}{ Shaft Power Ratio } \\
\hline Identifier & Take-Off & $\begin{array}{l}\text { Take-Off } \\
\text { to Climb }\end{array}$ & Climb & Cruise & Descent & Approach & Landing \\
\hline Shaft Set 1 & 0.30 & 0.30 & 0.30 & 0.30 & 0.10 & 0.10 & 0.10 \\
\hline \multicolumn{8}{|c|}{ Supplied Power Ratio } \\
\hline Identifier & Take-Off & $\begin{array}{l}\text { Take-Off } \\
\text { to Climb }\end{array}$ & Climb & Cruise & Descent & Approach & Landing \\
\hline Supplied Set 1 & 0.76 & 0.76 & 0.76 & 0.00 & 0.13 & 0.13 & 0.13 \\
\hline Supplied Set 2 & 0.38 & 0.38 & 0.38 & 0.09 & 0.09 & 0.00 & 0.00 \\
\hline Supplied Set 3 & 0.47 & 0.31 & 0.47 & 0.08 & 0.08 & 0.00 & 0.00 \\
\hline
\end{tabular}

The typical missions here proposed are reported in the following tables. Conclusions about the three simulations can be derived from the different sets of supplied power ratio considered.

Table 10 Typical mission profile with take-off weight of $22973 \mathrm{~kg}$ (block fuel of $415 \mathrm{~kg},-22 \%$ ).

\begin{tabular}{lccccc}
\hline \hline & \multicolumn{5}{c}{ Typical Mission } \\
\hline Identifier & $\begin{array}{c}\text { Time } \\
(\mathbf{m i n})\end{array}$ & $\begin{array}{c}\text { Range } \\
(\mathbf{k m})\end{array}$ & $\begin{array}{c}\text { Fuel } \\
(\mathbf{k g})\end{array}$ & $\begin{array}{c}\text { Shaft Power } \\
\text { Ratio }\end{array}$ & $\begin{array}{c}\text { Supplied } \\
\text { Power Ratio }\end{array}$ \\
\hline Take-Off & 0.27 & 0.605 & 2.24 & 0.30 & 0.76 \\
Take-Off to Climb & 3.15 & 15.255 & 22.47 & 0.30 & 0.76 \\
Climb & 7.06 & 46.463 & 38.70 & 0.30 & 0.76 \\
Cruise & 22.94 & 193.959 & 238.50 & 0.30 & 0.00 \\
Descent & 17.68 & 114.735 & 97.34 & 0.10 & 0.13 \\
Approach & 2.13 & 8.430 & 14.81 & 0.10 & 0.00 \\
Landing & 0.35 & 0.760 & 0.52 & 0.10 & 0.00 \\
\hline \hline
\end{tabular}


Table 11 Typical mission profile with take-off weight of $22938 \mathrm{~kg}$ (block fuel of $387 \mathrm{~kg},-27 \%$ ).

\begin{tabular}{lccccc}
\hline \hline & \multicolumn{5}{c}{ Typical Mission } \\
\hline Identifier & $\begin{array}{c}\text { Time } \\
(\mathbf{m i n})\end{array}$ & $\begin{array}{c}\text { Range } \\
(\mathbf{k m})\end{array}$ & $\begin{array}{c}\text { Fuel } \\
(\mathbf{k g})\end{array}$ & $\begin{array}{c}\text { Shaft Power } \\
\text { Ratio }\end{array}$ & $\begin{array}{c}\text { Supplied Power } \\
\text { Ratio }\end{array}$ \\
\hline Take-Off & 0.28 & 0.611 & 3.36 & 0.30 & 0.38 \\
Take-Off to Climb & 3.20 & 15.531 & 30.10 & 0.30 & 0.38 \\
Climb & 6.92 & 45.494 & 48.49 & 0.30 & 0.38 \\
Cruise & 22.84 & 194.678 & 183.67 & 0.30 & 0.09 \\
Descent & 17.68 & 114.706 & 105.01 & 0.10 & 0.09 \\
Approach & 2.13 & 8.430 & 15.38 & 0.10 & 0.09 \\
Landing & 0.35 & 0.763 & 0.56 & 0.10 & 0.09 \\
\hline \hline
\end{tabular}

Table 12 Typical mission profile with take-off weight of $22950 \mathrm{~kg}$ (block fuel of $390 \mathrm{~kg},-26 \%$ ).

\begin{tabular}{lccccc}
\hline \hline Identifier & Time & Range & Fuel & Shaft Power & Supplied Power \\
Ratio & Ratio \\
\hline Take-Off & 0.28 & 0.609 & 3.03 & 0.30 & 0.47 \\
Take-Off to Climb & 3.05 & 14.943 & 31.74 & 0.30 & 0.31 \\
Climb & 6.96 & 45.784 & 42.80 & 0.30 & 0.47 \\
Cruise & 22.90 & 195.079 & 191.47 & 0.30 & 0.08 \\
Descent & 17.66 & 114.605 & 104.90 & 0.10 & 0.08 \\
Approach & 2.13 & 8.430 & 15.40 & 0.10 & 0.08 \\
Landing & 0.36 & 0.771 & 0.56 & 0.10 & 0.08 \\
\hline \hline
\end{tabular}

The first typical mission proposed in Table 10 does not include the use of battery along the cruise phase. This strategy takes advantage from a thermal engine working at its condition of maximum efficiency while supplying the necessary additional power by e-storage in those flight phases where the specific fuel consumption is higher. However, even if this could sound reasonable, the benefits related to this strategy are limited by the short amount of time related to take-off and climb with respect to the cruise phase. In fact, as shown by the second typical mission (Table 11), a higher fuel saving percentage can be reached only by reducing the fuel burned during cruise. The last typical mission, whose results are reported in Table 12, underlies the direct dependence of the fuel saving percentage from the cruise phase supplied power ratio.

The design mission is provided phase by phase in Table 13. As discussed previously, the design mission is a small portion of the total number of missions the aircraft flies during its operative life, thus, it has a minor importance on the objective of research projects to design greener platforms. However, since it could be a limiting factor for airlines acquisition, maintenance and transfer operations, the same operative flexibility of the reference aircraft is tested.

Table 13 Design mission profile.

\begin{tabular}{lccccc}
\hline \hline \multicolumn{7}{c}{ Design Mission } \\
\hline Identifier & $\begin{array}{c}\text { Time } \\
(\mathbf{m i n})\end{array}$ & $\begin{array}{c}\text { Range } \\
(\mathbf{k m})\end{array}$ & $\begin{array}{c}\text { Fuel } \\
(\mathbf{k g})\end{array}$ & $\begin{array}{c}\text { Shaft Power } \\
\text { Ratio }\end{array}$ & $\begin{array}{c}\text { Supplied } \\
\text { Power Ratio }\end{array}$ \\
\hline Take-Off & 0.40 & 0.839 & 7.96 & 0.30 & 0.05 \\
Take-Off to Climb & 5.69 & 28.680 & 96.81 & 0.30 & 0.05 \\
Climb & 14.17 & 94.324 & 181.89 & 0.30 & 0.05 \\
Cruise & 102.51 & 873.654 & 1043.83 & 0.30 & 0.05 \\
Descent & 16.80 & 114.588 & 100.51 & 0.10 & 0.05 \\
Approach & 2.00 & 8.002 & 14.63 & 0.10 & 0.05 \\
Landing & 0.37 & 0.806 & 0.56 & 0.10 & 0.05 \\
\hline \hline
\end{tabular}

An aspect that is here highlighted deals with the performance constraints: if, on one hand, the all-engine operative conditions (AEO) are strongly penalized by the increment of weight, on the other hand, the one-engine inoperative conditions (OEI) takes the benefits related to two power sources. In fact, in the present case, considering the failure of one thermal engine, the propulsive power is not halved. The e-storage can supply, up to the sizing power of each 
component of the powertrain, a surplus of power. Moreover, the presence on the same shaft of the thermal engine of a e-motor drive would permit the propeller to preserve its functionality even when the gasturbine is shut down.

Table 14. Performance of the hybrid-electric concept.

\begin{tabular}{lcc}
\hline \hline & Value & Unit \\
\hline Take-Off run & 839 & $\mathrm{~m}$ \\
Landing run & 806 & $\mathrm{~m}$ \\
Balanced Field Length & 979 & $\mathrm{~m}$ \\
Ceiling altitude OEI & 15094 & $\mathrm{ft}$ \\
Ceiling altitude AEO & 31114 & $\mathrm{ft}$ \\
\hline \hline
\end{tabular}

\section{Conclusion}

The present work provides the necessary background for the design of hybrid-electric aircraft moving from an already flying platform by exploring the possible concepts for a certain set of frozen requirements driven by the market segment and industrial necessity. The importance of this type of study deal with the renewal of the global fleet to greener technologies in short time. Results demonstrate that even in case of minor changes, considering a state-of-theart technological level, a fuel saving percentage around -27\% (Table 11) is still possible, but it lies in the wise use of the e-storage energy along the flight path.

\section{Acknowledgments}

This research work has been inspired and partly financed by the IRON (Innovative turbopROp configuratioN) project implemented by CS2 European project GAM-2020-REG (Project ID: 945548) for year 2020-2022. The authors would like to thank all partners of the consortium led by CIRA for the useful feedback and Leonardo Aircraft as topic leader for useful suggestions and indications. The content of this paper reflects only the author's view and both the European Commission and the Clean Sky 2 Joint Undertaking are not responsible for any use that may be made of the information it contains.
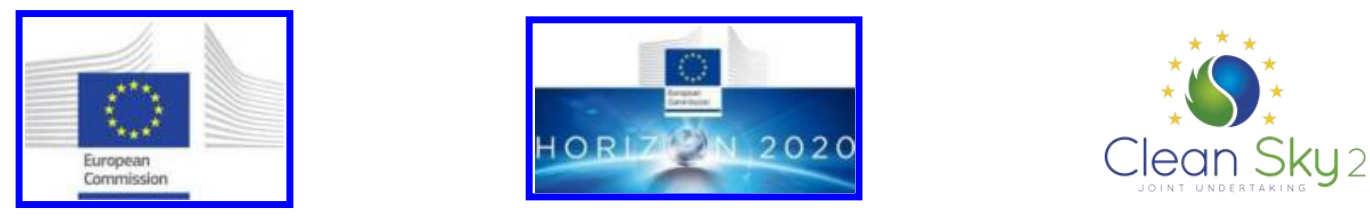

\section{References}

-[1] Antcliff, K. R., and Capristan, F. M. Conceptual Design of the Parallel Electric-Gas Architecture with Synergistic Utilization Scheme (PEGASUS) Concept. 2017.

[2] Bradley, M. K., and Droney, C. K. Subsonic Ultra Green Aircraft Research : Phase I Final Report. 2011.

[3] Orefice, F., Corcione, S., Nicolosi, F., Ciliberti, D., and Rosa, G. De. Performance Calculation for HybridElectric Aircraft Integrating Aero-Propulsive Interactions. 2021.

[4] EASA. "Certification Specifications for Normal, Utility, Aerobatic and Commuter Category Aeroplanes CS23.” No. July, 2012, p. 482.

[5] EASA. Certification Specifications and Acceptable Means of Compliance for Large Aeroplanes CS-25. 2018.

-[6] Orefice, F., Della Vecchia, P., Ciliberti, D., and Nicolosi, F. "Correction: Aircraft Conceptual Design Including Powertrain System Architecture and Distributed Propulsion.” No. August, 2019, pp. 1-20. https://doi.org/10.2514/6.2019-4465.c1.

[7] Nicolosi, F., Corcione, S., Trifari, V., and De Marco, A. "Design and Optimization of a Large Turboprop Aircraft.” Aerospace, 2021. https://doi.org/10.3390/aerospace8050132.

[8] Lefebvre, T., Bartoli, N., Dubreuil, S., Panzeri, M., Lombardi, R., Della Vecchia, P., Stingo, L., Nicolosi, F., De Marco, A., Ciampa, P. D., Anisimov, K., Savelyev, A., Mirzoyan, A., and Isyanov, A. Enhancing Optimization Capabilities Using the AGILE Collaborative MDO Framework with Application to Wing and Nacelle Design. Progress in Aerospace Sciences. 
-[9] Antcliff, K. R., and Capristan, F. M. "Conceptual Design of the Parallel Electric-Gas Architecture with Synergistic Utilization Scheme (PEGASUS) Concept." 18th AIAA/ISSMO Multidisciplinary Analysis and Optimization Conference, 2017, No. June, 2017, pp. 1-15. https://doi.org/10.2514/6.2017-4001.

-[10] de Vries, R., Brown, M. T., and Vos, R. "A Preliminary Sizing Method for Hybrid-Electric Aircraft Including Aero-Propulsive Interaction Effects." 2018 Aviation Technology, Integration, and Operations Conference, 2018, pp. 1-29. https://doi.org/10.2514/6.2018-4228.

[11] Mardanpour, P., and Hodges, D. H. "On the Importance of Nonlinear Aeroelasticity and Energy Efficiency in Design of Flying Wing Aircraft.” Advances in Aerospace Engineering, 2015. https://doi.org/10.1155/2015/613962.

[12] Molyneux, W. G. Approximate Formulae for Flutter Prediction: With Particular Reference to Main Surface Flexure-Torsion Flutter in the Transonic Region. Aircraft Engineering and Aerospace Technology.

[13] De Marco, A., Di Stasio, M., Della Vecchia, P., Trifari, V., and Nicolosi, F. "Automatic Modeling of Aircraft External Geometries for Preliminary Design Workflows." Aerospace Science and Technology, 2020. https://doi.org/10.1016/j.ast.2019.105667.

[14] Marco, A. De, Trifari, V., Nicolosi, F., and Ruocco, M. "A Simulation-Based Performance Analysis Tool for Aircraft Design Workflows.” Aerospace, Vol. 7, No. 11, 2020. https://doi.org/10.3390/aerospace7110155.

-[15] Nicolosi, F., Ciliberti, D., Della Vecchia, P., and Corcione, S. "Experimental Analysis of Aircraft Directional Control Effectiveness.” Aerospace Science and Technology, 2020. https://doi.org/10.1016/j.ast.2020.106099. 